[Agr. Biol. Chem., Vol. 26, No. 7. p. 417 423, 1962]

\title{
Polarographic Determination of Respiratory Activity with Clark Oxygen Electrode
}

\author{
By Hisateru Mitsuda, Kazuo Murakami and Fumio Kawai \\ Laboratory of Nutritional Chemistry, Faculty of Agriculture, Kyoto University, Kyoto
}

Received February 2, 1962

\begin{abstract}
The authors have developed a polarographic technique in which Clark oxygen electrode (stationary platinum electrode covered with a polyethylene membrane) is employed for the determination of respiratory activity. The procedure of the operation is very simple, yet it was highly sensitive to the changes of the oxygen concentration in the solution, and the value of current was proportional to the oxygen concentration. The respiratory activity and control of rat liver mitochondria could be determined satisfactorily by this method.
\end{abstract}

\section{INTRODUCTION}

Manometric method has been used extensively for the determination of respiratory activity, but polarographic technique has many advantages in the observation of the initial stage of a reaction and for a sensitive detection of a small change of oxygen concentration. Two kinds of apparatus with a vibrating platinum electrode $\mathrm{e}^{1}$ or a rotating platinum electrode ${ }^{2)}$ have been used for the polarographic method. These apparatus were found to be very sensitive, but their mechanisms were complicated and its operation required extreme care and caution.

Clark and his co-workers ${ }^{3)}$ have developed a method for a continuous recording of oxygen tension in blood by polarography in which a platinum cathode is covered with a cellophane membrane. It was noted that the membrane prevented the electrode surface from inevitable contamination and minimized the poor stability usually accompanied with the polarographic measurement of oxy-

1) B. Chance, J. Biol. Chem., 217, 383 (1955).

2) B. Hagihara, Biochem. Biophys. Acta, 46, 134 (1961)

3) L.C. Clark, et al. J. Appl. Physiol., 6, 189 (1953). gen with platinum electrode.

The authors tried, therefore, to apply the Clark's platinum electrode for the polarographic determination of respiratory activity. The polarographic apparatus with a Clark oxygen electrode to be described in the present paper was found to be satisfactory with respect to both the sensitivity for the changes of oxygen concentration and the simplicity of operation.

\section{EXPERIMENTAL}

\section{Materials and Methods}

ADP (sodium salt), purchased from Sigma Chemical Co. Ltd. was $99 \%$ pure and used without further purification. Nitrogen gas from a cylinder was purified by bubbling into the saturated sodium hydroxide solution containing $10 \%$ pyrogallol. The other reagents used were of analytical grade. The glass redistilled water was used throughout the experiment. The mitochondrial preparation of normal rat liver was obtained by the method of Lardy ${ }^{4}$ et al., and suspended in the mixture of $60 \mathrm{~mm}$ sucrose, $190 \mathrm{~mm}$ mannitol, $0.2 \mathrm{~mm}$ EDTA and $10 \mathrm{~mm}$ Trishydrochloride buffer, $\mathrm{pH}$ 7.3. One $\mathrm{ml}$ of mitochondrial suspension which was preserved in a beaker

4) H.A. Lardy, J. Biol. Chem., 195, 215 (1952). 
in a thin layer (about $5 \mathrm{~mm}$ ) at $0^{\circ} \mathrm{C}$, was equivalent to $2 \mathrm{~g}$ of fresh liver.

The nitrogen contents of the mitochondria were determined by the semimicro Kjeldahl method. The pH 7.3 buffer used for the reaction was an isotonic solution which consisted of $84 \mathrm{~mm}$ potassium chloride, $3 \mathrm{~mm}$ monopotassium phosphate, $13 \mathrm{~mm}$ disodium phosphate, $6 \mathrm{~mm}$ magnesium chloride and $12 \mathrm{~mm}$ sodium fluoride.

The oxygen concentration of the buffer was estimated to be $240 \mu$ moles per liter at $25^{\circ} \mathrm{C}$.

\section{Apparatus.}

The circuit of the apparatus is shown in Fig. 1 . A constant voltage derived from a dry cell, $1.5 \mathrm{~V}$ and a variable resistance was applied across the oxygen electrode through the Polaro-Recorder (PR-II type. Yanagimoto Co. Ltd.). The indicator electrode was the Clark oxygen electrode manufactured by Yellow Spring Instrument Company. The inner part of the electrode was filled with the saturated potassium chloride solution containing a trace amount of Aerosol IB, and the tip of it was covered tightly with a thin polyethylene membrane. The jacketed reaction vessel having the center well, $2 \mathrm{~cm}$ in diameter and $3 \mathrm{ml}$ in capacity, was maintained at a constant temperature by circulatory water from a bath.

Usually, the vessel of an open type was used in

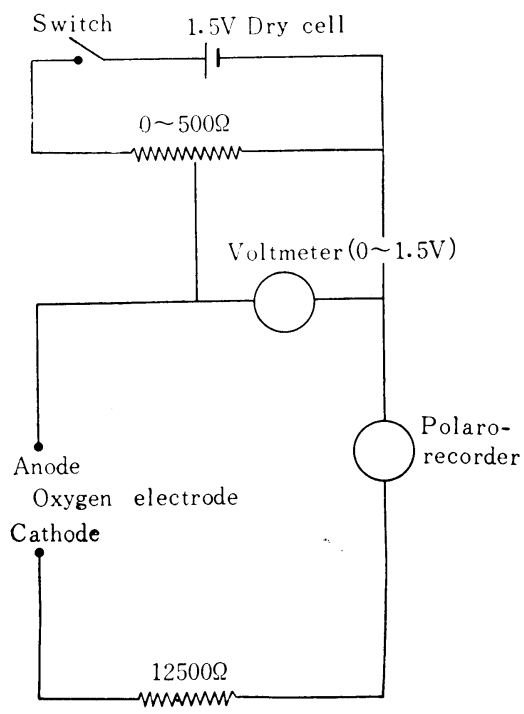

FIG. 1. Gircuit of Apparatus for Clark Oxygen Electrode. which the reaction medium contacted with the outside air freely. So that, the effect of the dissolution of the air oxygen into the reaction medium should be considered. This effect is discussed later.

\section{Procedure.}

The electrode was set in the buffer which was stirred by a magnetic stirrer. Immediately after the switch of the circuit was turned on, a very high excessive current was observed to flow, but after thirty to sixty seconds elapsed, the electrode current reached a constant value. This was the true value of the current which corresponded to the concentration of oxygen as shown later in Fig. 3. The current sensitivity of the recorder was $1 \mu \mathrm{A}$ per $100 \mathrm{~mm}$. The respiration process was followed with the addition of the mitochondrial suspension and ADP into the buffer-substrate solution.

\section{RESULTS}

\section{Preliminary Experiment for the Determination} of Oxygen.

(a) Polarogram of oxygen: Current-voltage curve of oxygen in the air-saurated buffer is shown in Fig. 2. Each value on these plots was obtained after electrolytic current attained to a stationary value at each applied voltage. Current intensity increased with the rise of the applied voltage to negative value up to $-0.4 \mathrm{~V}$, but reached a con-

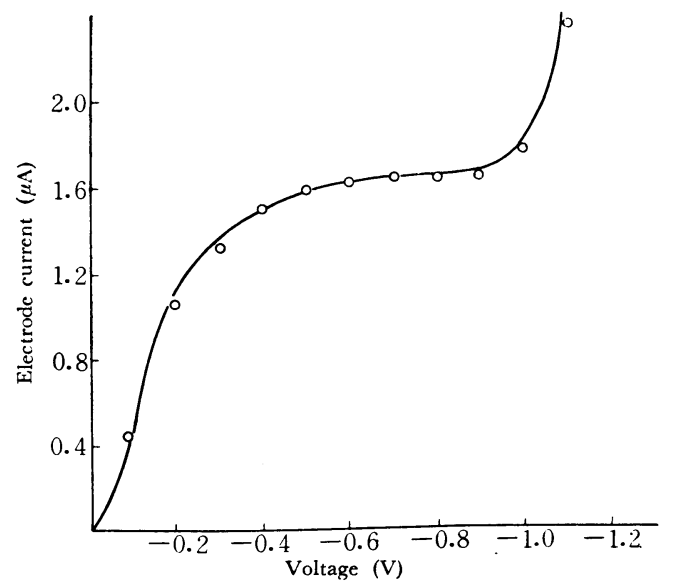

FIG. 2. Voltage-Current Curve of Oxygen after Reaching Equilibrium.

Room temperature, ca. $17^{\circ} \mathrm{C}$. 
stant value in the range of -0.5 to $-0.9 \mathrm{~V}$, and increased again abruptly when the voltage was raised above $-1.0 \mathrm{~V}$. This pattern is a typical current-voltage curve of oxygen. From these data, $--0.6 \mathrm{~V}$ was chosen for the determination of the oxygen concentration in the following experiments.

(b) Relationship between the values of electrode current and the oxygen concentration in the buffer: The proportionality between the values of current and the oxygen concentration was investigated under the constant voltage of $-0.6 \mathrm{~V}$. As illustrated in Fig. 3 after electrolytic current reached a stationary value in $2 \mathrm{ml}$ of an air saturated buffer, nitrogen gas was bubbled into the buffer to exhaust oxygen. The levels of the current diminished abruptly and fallen to zero after the elapse of about three minutes.

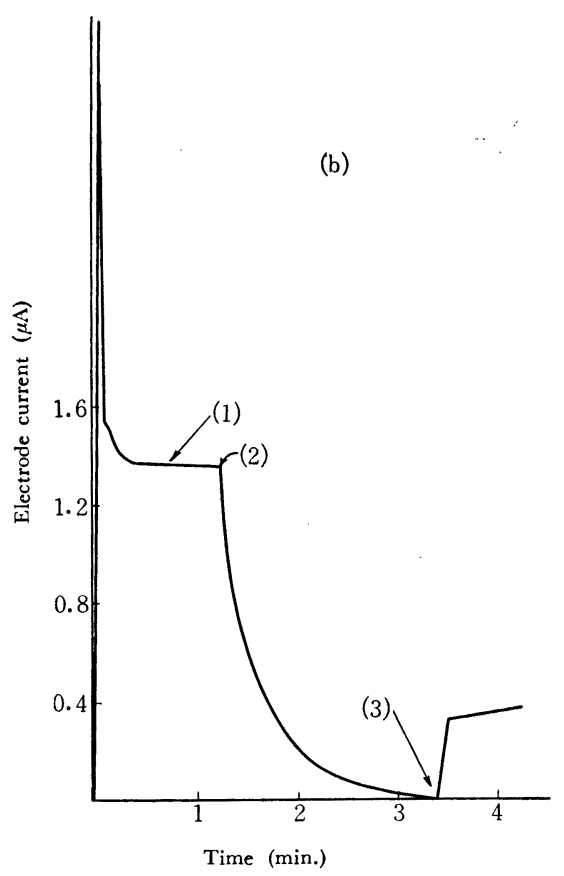

FIG. 3. Calibration of Clark Oxygen Electrode. Room temperature, $17^{\circ} \mathrm{C}$

(a) (1) Air saturated buffer $(2.0 \mathrm{ml}$ ) (b) (1) Air saturated buffer $(4.0 \mathrm{ml})$
At this point, as shown in Fig. 3 (a), $8 \mathrm{ml}$ of the air saturated buffer was added again into the above buffer which was free from oxygen, and so the value of current increased instantly and reached a constant value which corresponds to the final oxygen concentration. In Fig. $3(\mathrm{a})$, the concentration of oxygen in this buffer was calculated to be $80 \%$ of that in the original air saturated buffer, while the value of current corresponded to $75 \%$ of that in the original. Also, analogous data were obtained in Fig. 3 (b), in which the oxygen concentration was varied to $29 \%$, while the value of current corresponded to $26 \%$. Similar experiments were carried out in the same manner at different oxygen concentrations and the values of current were plotted against the concentration of oxygen.

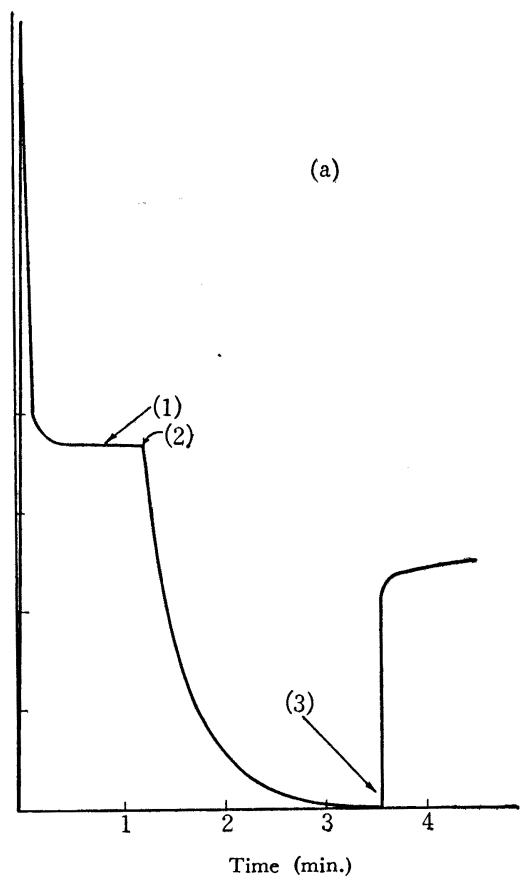

(2) $\mathrm{N}_{2}$ bubbling. (3) $8 \mathrm{ml}$ buffer.

(2) $\mathrm{N}_{2}$ hubbling. (3) $1.5 \mathrm{ml}$ buffer. 
A linear relationship was obtained as shown in Fig. 4. From these data, it was known that the apparatus was responding to the changes of oxygen concentration with a satisfactory speed and accuracy.

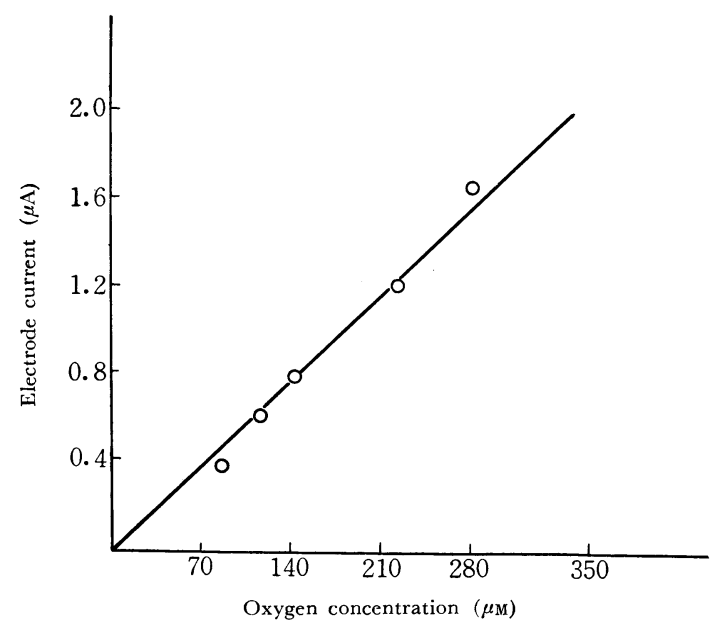

FIG. 4. Relation Between Oxygen Concentration and Electrode Current.

Room temperature, $17^{\circ} \mathrm{C}$

2. Determination of Respiratory Activity of Rat Liver Mitochondria.

From these results, it was confirmed that this equipment could be used for our purpose. Therefore, the respiratory activity was followed by this equipment. When succinate, $a$-ketoglutarate, glutamate and $\beta$-hydroxybutyrate were used as substrate, the courses of the reaction were as shown in Fig. 5 (a, b, c, d), respectively. After the current reached stationary state in the airsaturated substrate-buffer solution which consisted of $1.8 \mathrm{ml}$ of isotonic buffer solution and $0.1 \mathrm{ml}$ of $100 \mathrm{~mm}$ substrate (final concentration, $5 \mathrm{~mm}$ ), $0.1 \mathrm{ml}$ of the mitochondrial suspension was added into the solution. An abrupt decrease of oxygen concentration occurred. It was mainly caused by the dilution of oxygen in the reaction medium by the addition of the oxygen deficient mitochondri-

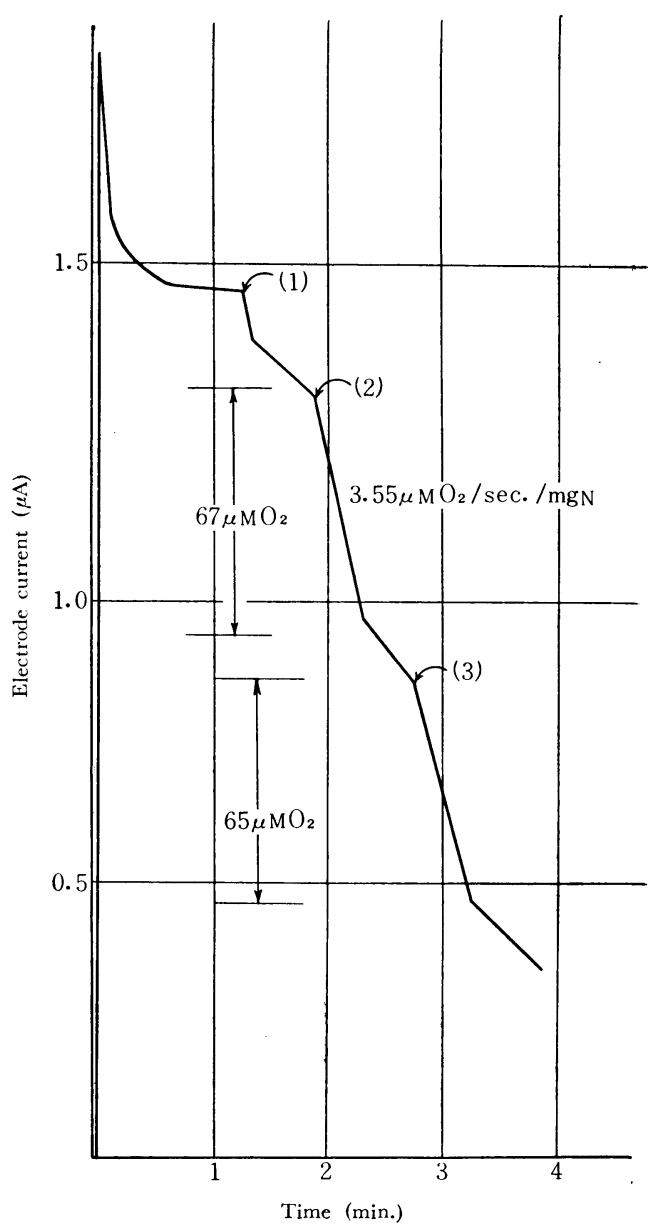

FIG. 5 (a). Respiratory Activity of Normal Rat Liver Mitochondria (Succinate).

Temperature, $25^{\circ} \mathrm{C}$

$$
\begin{aligned}
& \text { ADP : } 0=1.7: 1 \\
& \text { (1) } 0.1 \mathrm{ml} \text { mitochondria. } \\
& \text { (2) } 225 \mu_{\mathrm{M}} \wedge \mathrm{DP} \\
& \text { (3) } 225 \mu_{\mathrm{M}} \mathrm{ADP}
\end{aligned}
$$

al suspension. Following this, there appeared a slow oxygen consumption. This slow respiration was quickly accelerated (about four to six times) by the addition of $0.025 \mathrm{ml}$ of $18 \mathrm{mM}$ ADP (final concentration, $225 \mu \mathrm{M}$ ) and, immediately after all added ADP was phosphorylated, the accelerated respiration was brought back to the original one. These are typical examples of the so-called respira- 
tory control. When succinate was used as substrate, the ratio of the amounts of added ADP and consumed oxygen (ADP : O) was calculated to be $1.7: 1$. The amount of consumed oxygen was the mean value of those caused by two ADP additions. The ADP : O ratio was equal to $P$ : $O$ ratio, which is usually used as a criterion of the respiratory activity. Similarly, when $a$-ketoglutarate, glutamate and $\beta$-hydroxybutyrate were used as substrate, the ratios of ADP : O were calculated to be $2.8: 1,2.7: 1$ and $2.5: 1$ respectively as shown

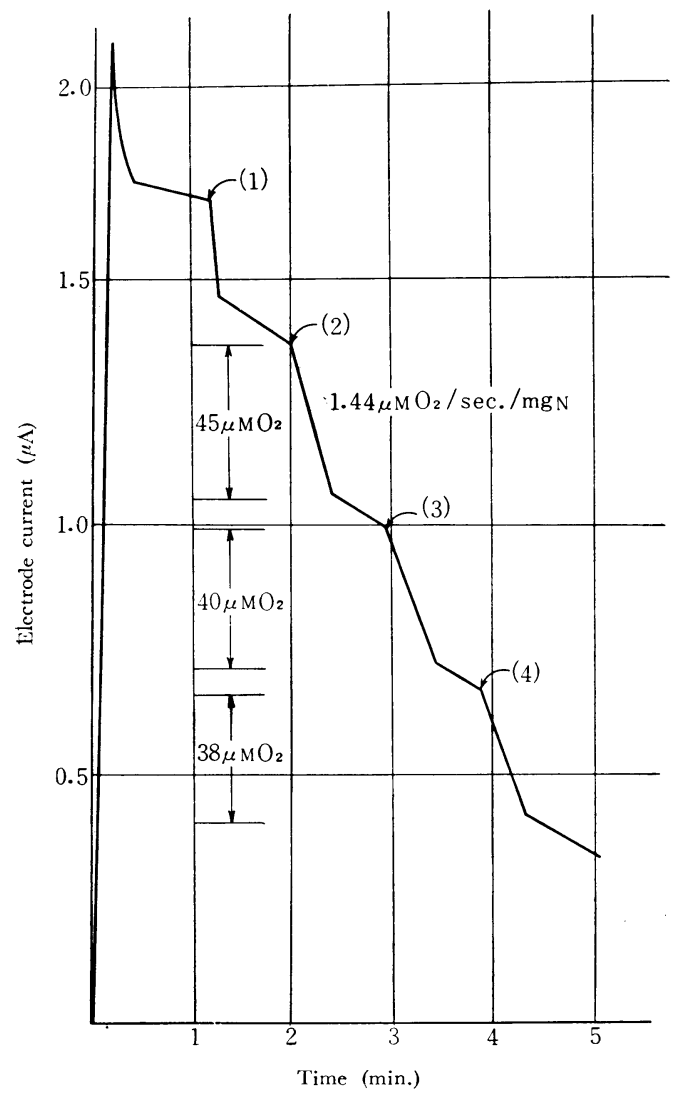

FIG. 5 (b). Respiratory Activity of Normal Rat Liver Mitochondria ( $\alpha$-Ketoglutarate).

$$
\begin{aligned}
& \text { Temperature, } 25^{\circ} \mathrm{C} \\
& \text { ADP : } 0=2.8: 1 \\
& \text { (1) } 0.15 \mathrm{ml} \text { mitochondria } \\
& \text { (2) } 225 \mu_{\mathrm{M}} \text { ADP } \\
& \text { (3) } 225 \mu_{\mathrm{M}} \text { ADP } \\
& \text { (4) } 225 \mu_{\mathrm{M}} \text { ADP }
\end{aligned}
$$

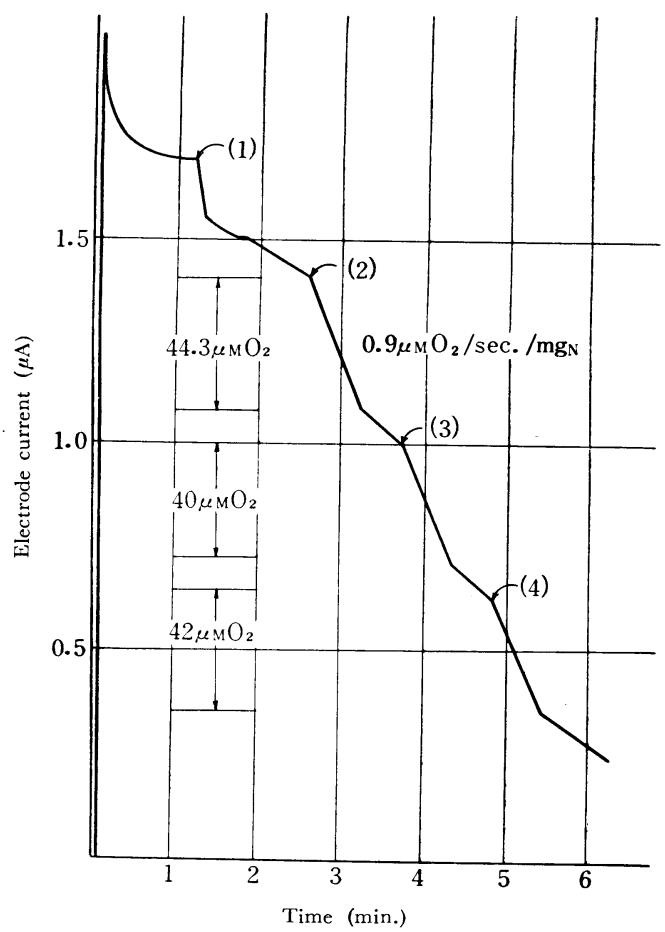

FIG. 5 (c). Respiratory Activity of Normal Rat Liver Mitochondria (Glutamate).

Temperature, $25^{\circ} \mathrm{C}$

ADP : $0=2.7: 1$

(1) $0.2 \mathrm{ml}$ mitochondria

(2) $225 \mu_{\mathrm{M}} \mathrm{ADP}$

(3) $225 \mu_{\mathrm{M}} \mathrm{ADP}$

(4) $225 \mu_{\mathrm{M}} \mathrm{ADP}$

in Fig. 5 (b, c, d).

The effects of mitochondria concentration and ADP concentration on the respiratory rate and the ratio of $\mathrm{ADP}: \mathrm{O}$ were investigated. As shown in Fig. 6, the respiratory rate was directly proportional to the amounts of mitochondria over the range of $0.16 \mathrm{mg}$ to $0.96 \mathrm{mg}$ nitrogen. While, in the range of $100 \mu \mathrm{M}$ to $460 \mu \mathrm{M}$ of ADP concentration, the respiratory rate was constant and the amount of the consumed oxygen was proportional to the amount of the added ADP.

\section{DISCUSSIONS}

As shown in Table $\mathrm{I}$, the $\mathrm{P}$ : $\mathrm{O}$ ratio of each substrate determined was almost equal 


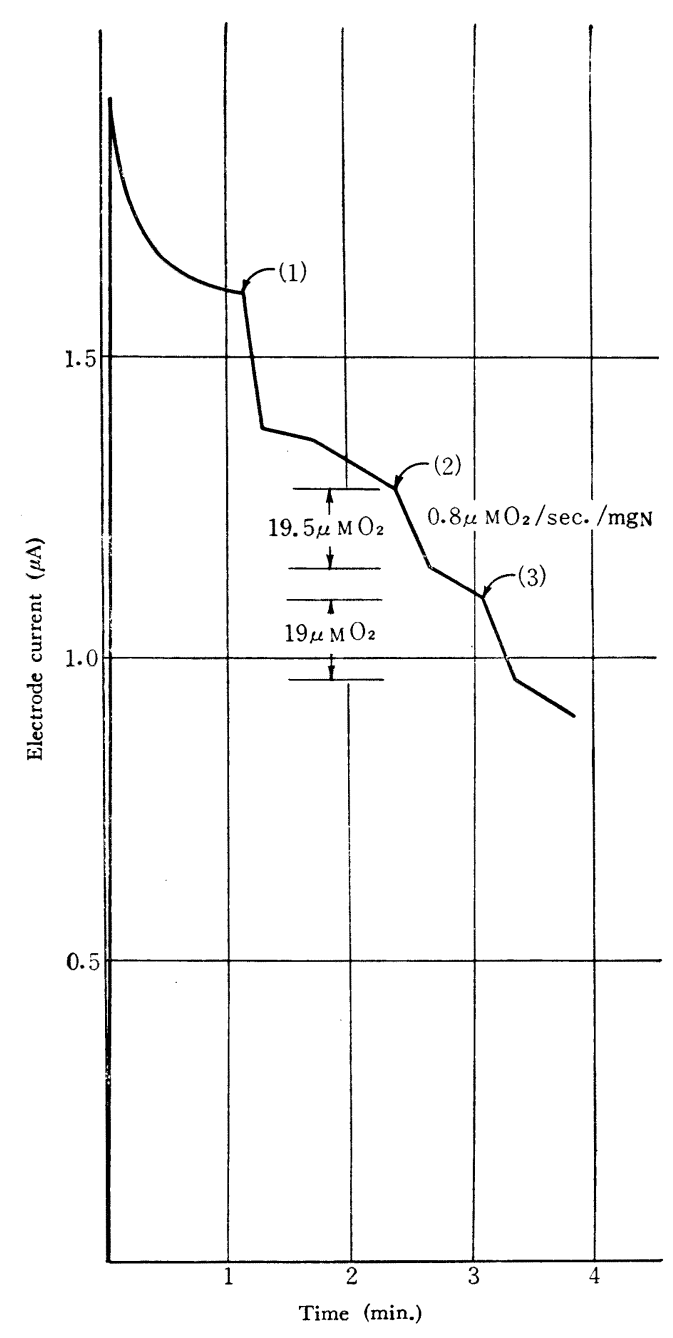

FIG. 5 (d). Respiratory Activity of Normal Rat Liver Mitochondria ( $\beta$-Hydroxybutyrate).

$$
\begin{aligned}
& \text { Temperature, } 25^{\circ} \mathrm{C} \\
& \text { ADP : } 0=2.5: 1 \\
& \text { (1) } 0.2 \mathrm{ml} \text { mitochondria } \\
& \text { (2) } 96 \mu_{\mathrm{M}} \text { ADP } \\
& \text { (3) } 96 \mu_{\mathrm{M}} \mathrm{ADP}
\end{aligned}
$$

to that obtained by other investigators using different apparatuses. Therefore, this polarographic method was satisfactory for the determination of the respiratory activity. When the oxygen electrode was used, however, there were certain problems about which one must be careful. In the first, it was the deteriora-

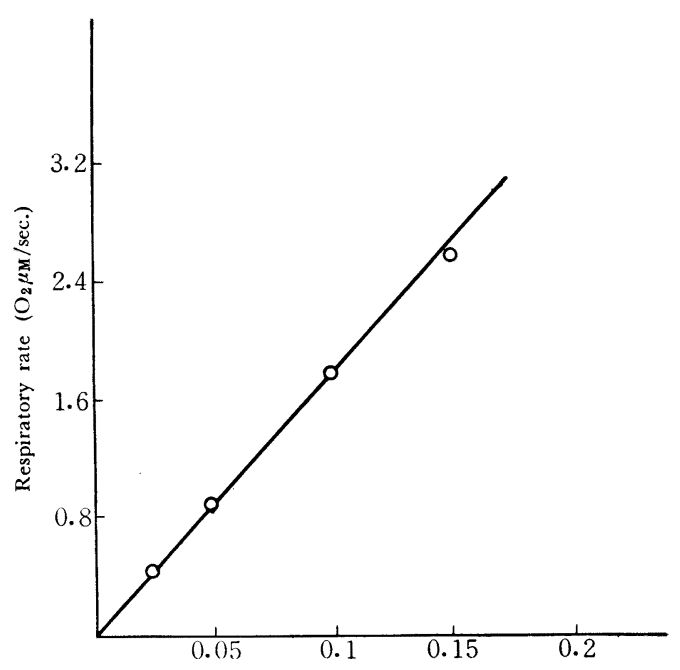

Mitochondria concentration $(\mathrm{ml}) \quad(0.1 \mathrm{ml}=0.32 \mathrm{mg} \mathrm{N})$

FIG. 6. Relation Between Mitochondria Concentration and Respiratory Rate (Succinate).

Room temperature, ca $17^{\circ} \mathrm{C}$ Substrate $=$ succinate

TABle I. Comparison OF P : O RATIOS
Substrate

Succinate $\boldsymbol{\alpha}$-Ketoglutarate

Glutamate $\beta$-Hydroxybutyrate

$$
P \text { : O ratios }
$$

$\begin{array}{ccc}\text { Present findings } & \text { Data by others } \\ 1.7 & \left.1.7^{5 \sim 7}\right) & 1.8^{1)} \\ 2.8 & & 3.0^{6)} \\ 2.7 & 2.6^{5)} & 3.1^{1)} \\ 2.5 & 2.5^{5,7)} & 2.6^{1,8}\end{array}$

tion of the oxygen electrode by the reaction medium (especially by mitochondrial protein in this case). This was protected almost perfectly by covering the platinum tip of cathode by a polyethylene membrane. In the second, it was the reliability of the response of the oxygen electrode to the change of the oxygen concentration. We set the electrode in the reaction medium which was stirred by a magnetic stirrer and made the response reliable enough to follow the oxygen consumption by mitochondria. In the third,

5) J.H. Copenhaver, JR. and H.A. Lardy, J. Biol. Chem., 195, 225 (1952).

6) H.A. Krebs, Biochem. J., 54, 107 (1951).

7) A.L. Lehninger. J. Biol. Chem., 190, 345 (1951).

8) D.R. Helinski and C. Cooper, ibid., 235, 3573 (1960). 
it was the dissolution of air oxygen into the reaction medium in which the reaction was in progress. This effect must be considered in the present experiment which was done with the open vessel. When about half of the dissolved oxygen was used, the rate of dissolution of air oxygen into the reaction medium was $0.12 \mu \mathrm{M} \mathrm{O} \mathrm{O}_{2}$ per second. Therefore, when the rate of respiration was very rapid at a high oxygen concentration in the reaction medium, the influence of the dissolution of air was negligible. But its effect was appreciable when the rate was slow at a low oxygen concentration in the medium.

\section{SUMMARY}

The respiratory activity of rat liver mitochondria was measured by a polarographic technique with the Clark oxygen electrode.

The procedure of the measurement is very simple, yet the electrode was as sensitive as the vibrating or the rotating platinum electrode to the change of the oxygen concentration in the solution.

The value of current was directly proportional to the oxygen concentration.

The so-called respiratory control could be followed satisfactorily by this apparatus.

The respiratory rate was directly proportional to the mitochondria concentration.

When succinate, $a$-ketoglutarate, glutamate and $\beta$-hydroxybutyrate were used as substrate, $\mathrm{P}: \mathrm{O}$ ratios were calculated to be $1.7: 1,2.8: 1,2.7: 1$ and $2.5: 1$, respectively.

\section{ADDENDUM}

Recently Bronk et al. ${ }^{9)}$ has announced the application of the Clark oxygen electrode to the estimation of the amount of oxygen consumed by mitochondrial fragments.

9) J.R. Bronk, Biochem. Biophys. Acta, 37, 327 (1960). 